\title{
Investigation of $\mathrm{SO}_{2}$ Adsorption of Graphene Oxide Fiber Bundle
}

\author{
Ilkay Ozsev Yuksek, Nuray Ucar, Nilgun Karatepe Yavuz, Aysen Onen
}

\begin{abstract}
This study focuses on the $\mathrm{SO}_{2}$ adsorption properties of graphene oxide fiber bundle. Graphene oxide fiber bundle was produced by $\mathrm{NaOH}$ reduction and Hummer's method, and $\mathrm{SO}_{2}$ adsorption tests were carried out. According to the SEM analysis and EDS Spectra, sulphur particles accumulated on the surface of the graphene oxide fibers were observed, in along with the result of the EDS spectra showing $6.7 \%$ sulphur content on the graphene oxide fibers. The absorption was also $102 \mathrm{mg}$ of $\mathrm{SO}_{2}$ per gram of sorbent (mg/gram) according to titration test.
\end{abstract}

Keywords-graphene oxide fiber bundle, $\mathrm{SO}_{2}$ adsorption

\section{Introduction}

One of the most hazardous gases people need to cope with is $\mathrm{SO}_{2}$, which is an industrial waste, that can cause acidic rains in along with greenhouse effect [1-3]. Gas sensors to detect $\mathrm{SO}_{2}$ and pollution control is the current focus of many researches; however, have a limitation of high temperature requirement [1,2]. Graphene, due to its high surface area, is thought to increase the amount of gas absorbed, and might give rise to the low-weight room temperature sensor applications [1]. The possibility of graphene, detecting various gasses have been reported by several researchers [3-5].

This study focuses on the $\mathrm{SO}_{2}$ adsorption and desorption properties of graphene oxide fiber bundle. The aim of the study is to investigate the $\mathrm{SO}_{2}$ adsorption properties of graphene oxide (GO) fiber bundle produced as a nonwoven film structure for possible applications on gas detectors and filtration. In the current literature, air and water filtration properties of graphene sheets and graphene coated fibers are studied; however, there is no source that can show the possibility of graphene oxide fibers for air filtration and gas detectors. With this study, we aim to develop of graphene oxide fiber based systems with $\mathrm{SO}_{2}$ adsorption properties for filtration and improve the gas filtration performance by the high surface area, and functional groups on the surface-

Ilkay Ozsev Yuksek, Nuray Ucar

Textile Engineering Department, Istanbul Technical University Turkey

\section{Nilgun Karatepe Yavuz}

Institute of Energy, Istanbul Technical University Turkey

Aysen Onen

Chemical Engineering Department, Istanbul Technical University Turkey

\section{Materials and Methods}

\section{A. Materials}

Nonwoven films were manufactured from reduced graphene oxide (GO) fiber bundles (Natural Flake Graphite, with $300 \mu \mathrm{m}$ fiber diameter and $20 \mu \mathrm{m}$ thickness). GO was prepared according to Hummer's method. Nonwoven structures were obtained from fibers drawn from GO dispersion in coagulation baths of containing $5 \% \mathrm{NaOH}$ by weight and water/ethanol solutions.

\section{B. Methods}

$\mathrm{SO}_{2}$ adsorption and desorption tests were carried out at quartz reactors on at the lab scale testing mechanism. SEM images and EDS spectroscopy was performed under SEM microscopy after $\mathrm{SO}_{2}$ adsorption.

$\mathrm{SO}_{2}$ adsorption tests were carried out with the $\mathrm{GO}$ fibers in the nonwoven form. The nonwoven surfaces were placed into the tubular oven inside the quartz reactor. Adsorption process was conducted at room temperature for 2 hours by feeding 150 $\mathrm{ml} / \mathrm{min}$ of $\mathrm{N}_{2}$ and $1.4 \mathrm{ml} / \mathrm{min} \mathrm{SO}_{2}$ gasses to the system. GO fibers were subjected to desorption process with the same system used for adsorption tests. Desorption process was conducted by the stepwise increase of the temperature at an interval of $5{ }^{\circ} \mathrm{C} / \mathrm{min}$ up to $360{ }^{\circ} \mathrm{C}$ for an hour. $\mathrm{N}_{2}$ gas feeding to the system with a volume of $150 \mathrm{ml} / \mathrm{min}$ was continued in desorption process. During desorption, the amount of $\mathrm{SO}_{2}$ adsorbed on GO nonwoven surface was determined by titration. The desorbed $\mathrm{SO}_{2}$ gas was accumulated by a gaswashing bottle, which contained $100 \mathrm{ml}$ of $\mathrm{H}_{2} \mathrm{O}_{2}$ (5\% by wt). At the end of the process, the amount of $\mathrm{H}_{2} \mathrm{SO}_{4}$ on the bottle was determined by titration and adsorbed $\mathrm{SO}_{2}$ amount was calculated from the $\mathrm{H}_{2} \mathrm{SO}_{4}$ amount.

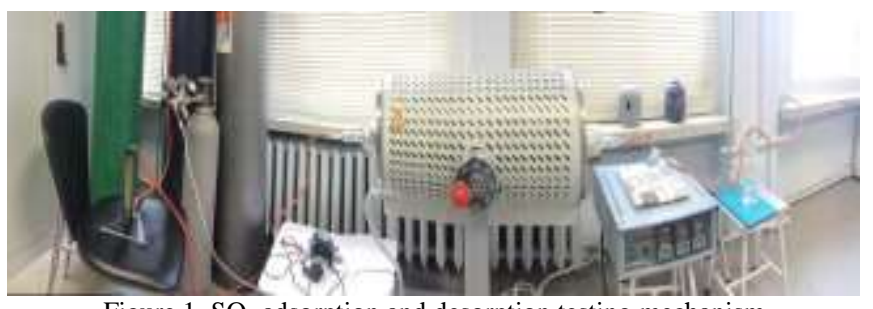

Figure $1 . \mathrm{SO}_{2}$ adsorption and desorption testing mechanism 


\section{Results and Discussion}

Fibers were coagulated in the coagulation bath for 2 minutes and has crimped structure with shrinkage. As a result of $\mathrm{NaOH}$ usage, the fibers were partially reduced and obtained a darker color as can be seen in Figure 2.

It was observed that the fibers adsorbed $102 \mathrm{mg}$ of $\mathrm{SO}_{2}$ sorbent gram $(\mathrm{mg} / \mathrm{g})$. The GO fiber bundle before and after the adsorption process is shown in Figure 3. As can be seen from the Figure 3, fibers shrunk and became more brittle after the desorption process at $360{ }^{\circ} \mathrm{C}$.

The $\mathrm{pH}$ level of the gas washing solution was measured as ph 1-2 after desorption. This might give rise to thought that absorbed $\mathrm{SO}_{2}$ on the sample might have successfully removed from the surface and accumulated on the gas washing solution. Figure 4 shows the gas washing solution before and after titration process, and as seen, the color of the solution changed from yellow to blue that proves the property of adsorbtion of $\mathrm{SO}_{2}$ gas was gained.

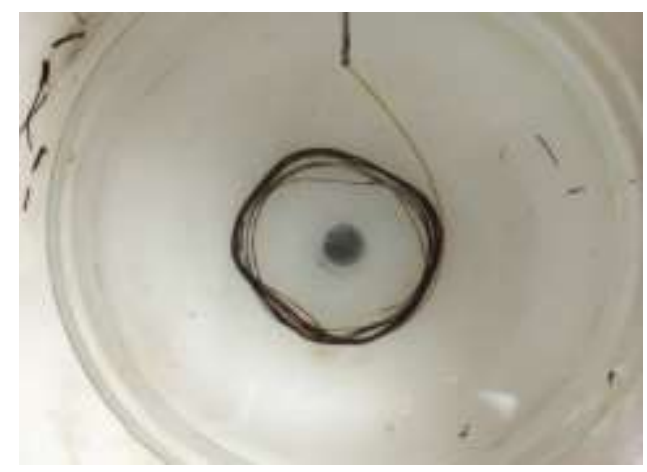

Figure 2. Change in fiber color after partial reduction

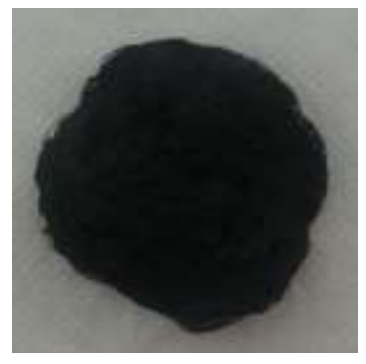

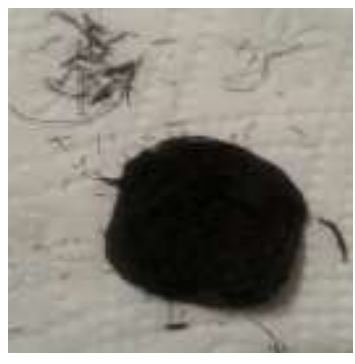

$\mathrm{b}$
Figure 3. The a)pre-adsorption and b) after desorption images of nonwoven surfaces obtained from coagulation in $\mathrm{pH} 7 \mathrm{NaOH}$ containing coagulation bath

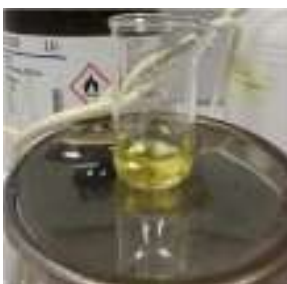

a

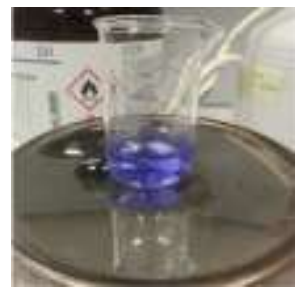

b
Figure 4. The gas washing solutions a) before titration b) after titration

After adsorption step, before the nonwoven surfaces proceed through desorption, SEM analysis in along with EDS spectra were carried out and the sulphur on the surface was proved. As can be seen from Figure 5, after $\mathrm{SO}_{2}$ adsorption, sulphur particles were accumulated on the surface and the amount of sulphur was found as $6.7 \%$ by EDS spectra shown in Figure 6.

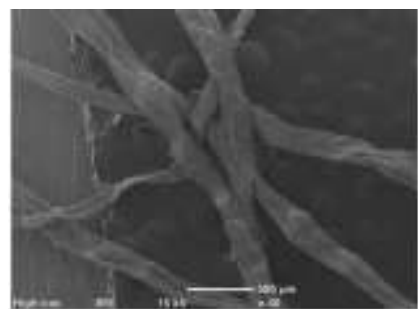

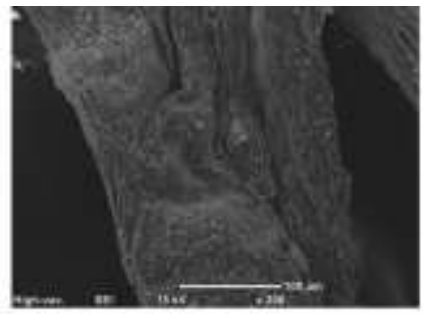

Figure 5. Fiber morphology after adsorption a-fiber structure, b- surface structure

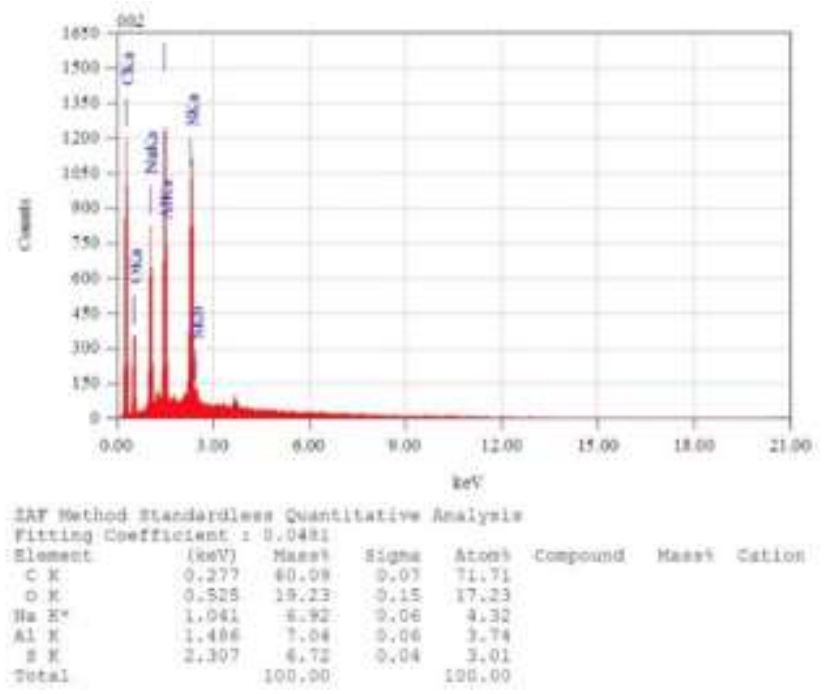

Figure 6. EDS spectra of nonwoven surfaces after adsorption 


\section{Conclusions}

To determine the possibility of use of graphene oxide fibers in gas sensors and detectors and filtration, the $\mathrm{SO}_{2}$ adsorption of graphene oxide nonwoven surfaces was investigated. Graphene oxide nonwoven surfaces was prepared by using Hummer's method continued with a $\mathrm{NaOH}$ reduction system. Shrinkage and brittleness of the fibers were observed. The amount of $\mathrm{SO}_{2}$ adsorbed on the fiber surface was found to be $6.7 \%$ according to EDS spectroscopy and sulphur particles on the surface was also observed in the SEM images. After the desorption process, the removal of the $\mathrm{SO}_{2}$ from graphene oxide nonwoven surface to gas washing solution was determined $102 \mathrm{mg}$ of $\mathrm{SO}_{2}$ per gram of solvent (mg/gram) was found to be adsorbed by the graphene oxide nonwoven surface.

\section{Acknowledgment}

This study is supported by TUBITAK (Project Number 114M524).

\section{References}

[1] S.S. Varghese, S.H. Varghese, S. Swaminathan, K.K. Singh and V. Mittal, Two-Dimensional Materials for Sens,ng: Graphene and Beyond, Electronics, 2015, 4, 651-687.

[2] G. Jimenez-Cadena, J. Riu and F.X. Rius, Gas Sensors Based on Nanostructured Materials, The Royal Society of Chemistry, Analyst, 2007, 132, 1083-1099.

[3] L. Shao, G. Chen, H. Ye, Y. Wu, Z. Qiao, Y. Zhu and H. Niu, Sulphur Dioxide Adsorbed on Graphene and Heteroatom-Doped Graphene: A First-Principles Study, Eur.Phys.J.B, 2013, 86:54.

[4] C. Xu, A. Cui, Y. Xu, X. Fu, Graphene Oxide - $\mathrm{TiO}_{2}$ Composite Filtration Membranes and Their Potential Application for Water Purification, Carbon, 62, 2013, 465-471.

[5] V. Stengl , S. Bakardjieva, T.M. Grygar, J. Bludska and M. Kormunda, $\mathrm{TiO}_{2}$-Graphene Oxide Nanocomposite as Advanced Photocatalytic Materials, Chemistry Central Journal, 2013, 7:41. 